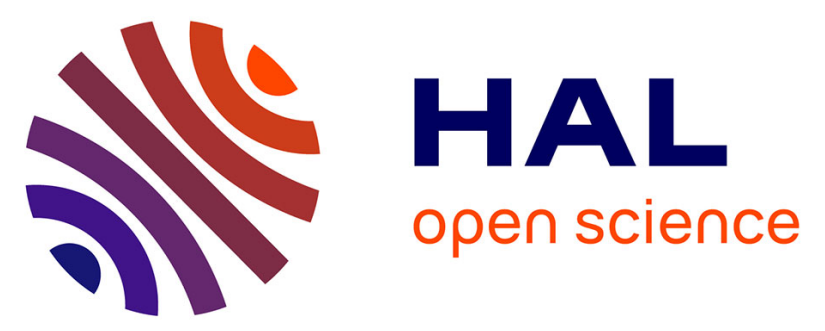

\title{
Yellowing of laser-cleaned artworks: Formation of residual hydrocarbon compounds after Nd:YAG laser cleaning of gypsum plates covered by lamp black
}

Jérémie Berthonneau, Philippe Parent, O. Grauby, Daniel Ferry, Carine Laffon, Alain Colombini, Blandine Courtois, Philippe Bromblet

\section{To cite this version:}

Jérémie Berthonneau, Philippe Parent, O. Grauby, Daniel Ferry, Carine Laffon, et al.. Yellowing of laser-cleaned artworks: Formation of residual hydrocarbon compounds after Nd:YAG laser cleaning of gypsum plates covered by lamp black. Journal of Cultural Heritage, 2019, 39, pp.57-65. 10.1016/j.culher.2019.02.014 . hal-02285084

\section{HAL Id: hal-02285084 https://hal.science/hal-02285084}

Submitted on 13 Sep 2019

HAL is a multi-disciplinary open access archive for the deposit and dissemination of scientific research documents, whether they are published or not. The documents may come from teaching and research institutions in France or abroad, or from public or private research centers.
L'archive ouverte pluridisciplinaire HAL, est destinée au dépôt et à la diffusion de documents scientifiques de niveau recherche, publiés ou non, émanant des établissements d'enseignement et de recherche français ou étrangers, des laboratoires publics ou privés. 
Yellowing of laser-cleaned artworks: formation of residual hydrocarbon compounds after Nd:YAG laser cleaning of gypsum plates covered by lamp black.

Jeremie BERTHONNEAU ${ }^{1 *}$, Philippe PARENT ${ }^{1 *}$, Olivier GRAUBY ${ }^{1}$, Daniel FERRY ${ }^{1}$, Carine LAFFON ${ }^{1}$, Alain COLOMBINI ${ }^{2}$, Blandine COURTOIS ${ }^{1}$ and Philippe BROMBLET ${ }^{2}$

${ }^{1}$ Aix-Marseille Université, CNRS - UMR 7325 CINaM (Centre Interdisciplinaire de Nanoscience de Marseille), Campus de Luminy, 13288 Marseille Cedex 9, France.

${ }^{2}$ CICRP Belle de Mai, 21 rue Guibal, 13003 Marseille, France. 
Title:

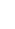

Yellowing of laser-cleaned artworks: formation of residual hydrocarbon compounds after Nd:YAG laser cleaning of gypsum plates covered by lamp black

Detailed plan of the article:

1. Introduction $\quad 3$

2. Research aims $\quad 3$

3. Materials and methods $\quad 4$

3.1. Sample preparation $\quad 5$

3.2. Laser cleaning $\quad 5$

3.3. $U V$-B exposure $\quad 5$

3.4. Spectrocolorimetry $\quad 5$

3.5. X-ray photoelectron spectroscopy 6

3.6. Fourier-transform infrared spectroscopy 6

3.7. $\quad$ Scanning electron microscopy and Transmission electron microscopy 7

$\begin{array}{ll}4 . & \text { Results }\end{array}$

5. Discussion $r$

$\begin{array}{lr}\text { 6. Conclusions } & 17\end{array}$

$\begin{array}{lr}\text { Acknowledgments } & 18\end{array}$

$\begin{array}{lr}\text { References } & 19\end{array}$ 


\section{Abstract:}

The removal of black crusts decaying the surface of artworks is an important concern for the conservation of cultural heritage. Nd:YAG laser cleaning of encrusted stones and plasters at $1064 \mathrm{~nm}$ is widely recognized as an effective restoration technique, but induces a noticeable yellowing of the surface. Several researches carried out on the effects of laser cleaning have been focused on the induced yellowing and how to visually mitigate this phenomenon. To this end, UV-B radiations were successfully used to lessen the laser-induced yellowing due to the removal of lamp black particles on gypsum. The mechanism at play for both the formation of the compounds yellowing the surface and their disappearance upon UV-B exposure remains, however, poorly understood. Within the frame of this research, we apply surface-sensitive characterization techniques to analyze the yellowed surface produced after Nd:YAG Q-Switched laser cleaning of lamp black deposit on a gypsum plate, and the same surface after UV-B exposure. A combination of X-ray photoelectron spectroscopy and Fouriertransformed infrared spectroscopy has been used to identify the residual carbon compounds responsible for the yellow coloration of the substrate. A nanoscale structural description of the ejected particles collected during the laser cleaning was finally performed with transmission electron microscopy. We found that the yellowing is due to partially oxidized hydrocarbons compounds deposited at the surface of the gypsum substrate. We propose that they form by reactions between carbon species emitted by the vaporization of the carbon particles, with hydrogen and oxygen produced by the dissociation of water molecules coming together from dehydration of the gypsum surface and from the water sprayed by the operator during cleaning.

\section{Keywords:}

Black crust/Laser cleaning/ XPS/FTIR/Electron microscopy/Restoration 


\section{Introduction}

Laser cleaning in restoration of artworks is a well-established and optimized technique [1,2]. Criticisms have, however, been expressed after its implementation due to the yellowish tint of the laser cleaned surfaces [3]. The phenomenon thus became a controversial issue as it was unclear whether it resulted from a specific side effect of laser cleaning [4] or from the revealing of a preexisting yellowish layer [5,6]. Many scientific investigations recently evidenced laser irradiation as the cause of the yellowing process and proposed ways to mitigate the discoloration pattern using poultices [7] or UV-B irradiation [8]. Nevertheless, the chemical composition as well as the formation mechanism of the compounds yellowing the surface remain enigmatic. As recently pointed out: "the exact nature of the material generated by laser treatment of black crust and contributing to the yellow color is still unknown" [9]. Several obstacles preclude the investigations. The material, phase or impurities at the origin of the yellowing are invisible and hardly analyzable using conventional techniques on thin sections. When analyses are carried out at the surface, only the substrate compounds are revealed without recognition of any neoformed phases $[1,2,9]$. The phases induced by laser cleaning are therefore assumed to be nano-sized and in a very low amount.

Black crusts forming at the interface between the substrate, the atmosphere and the polluted urban or industrial environment, have very complex compositions ranging from nano to sand size particles, minerals and organics, with a long list of chemical elements that are combined in various ways $[5,10]$. The interactions that may occur during a laser pulse are complex and the distinction between the initial black crust compounds and neoformed phases resulting from laser irradiation is far from obvious. A way to experimentally reproduce the phenomenon at play is (i) to make synthetic gypsum substrate, close to the epigenic gypsum layer systematically found beneath the black crust on carbonate stone surface $[8,9]$, (ii) to artificially cover this substrate with a layer containing a single specie sensitive to the laser, and (iii) to study the residues present on the yellowed surface after laser irradiation. Such model systems have been investigated by various authors, using a multi-scale approach from optical to electron microscopy coupled with energy-dispersed X-ray as well as electron energy loss spectroscopy to study the morphological, mineralogical and chemical features that could be linked to the yellowing 
phenomenon $[8,9,11,12]$. These studies brought new insights on the involvement of iron compounds and fly ashes in the yellowing phenomenon. Researches also showed that black crusts can be mimicked by lamp black nanoparticles, and that the laser-induced yellowing phenomenon is mitigated by UV-B irradiation $[8,11]$. The different processes at play along these treatments of gypsum plates covered with lamp black particles were carefully followed by spectrocolorimetry, but no information concerning the composition of the laser-induced yellow surface were gained up until now. Following this work, we have developed a specific analytical protocol capable of characterizing primary as well as neoformed nano-sized phases of lamp black upon the different treatments. A combination of X-ray photoelectron spectroscopy (XPS), Fourier-transform infrared spectroscopy (FTIR), scanning electron microscopy (SEM), and transmission electron microscopy (TEM) was applied to follow the chemical and morphological changes of a gypsum plate covered with lamp black, exposed to Nd:YAG Q-Switched laser cleaning at $1064 \mathrm{~nm}$ followed by UV-B irradiation at $313 \mathrm{~nm}$. These investigations bring new insights on the nature and origin of the laser-induced yellowing phenomenon.

\section{Research aims}

Beside its unquestionable advantages, the Nd:YAG laser cleaning of artworks yields to the yellowing of the treated surfaces. This study thus aims at understanding the mechanism at play in the laser-induced yellowing phenomenon by providing morphological, chemical, and structural characterizations of the primitive and the neo-formed carbon species on a model system. The ultimate objective consists in providing physico-chemical justifications for the simultaneous or consecutive use of UV-B exposure allowing for the progressive removal of the carbon compounds involved in the yellowing phenomenon.

\section{Materials and methods}

3.1 Sample preparation: Synthetic samples were elaborated with gypsum plaster plates manually covered with a thin layer of lamp black particles. The gypsum plates were made by hydration of pure 
hemihydrate (97\%, Acros organics) with distilled water (1/1 in mass). Windows (76 x $26 \mathrm{~mm})$ were cut in a dense foam template and glass microscope slides were placed at the bottom. The mixture (hemihydrate + distilled water) was then applied on the slides until the windows were filled. The surface was finally leveled with a spatula and the samples were left to dry for at least 24 hours. After demolding, the surface was covered with lamp black pigment (noir de fumée (C) supplied by Artech. Fine-grained black powder was applied dry with a brush to cover the gypsum plate with a black layer.

3.2 Laser cleaning: The plates were first cleaned with a Nd:YAG Q-Switched (QS) laser at 1064 $\mathrm{nm}$ (Thomson BM Industries NL201, $8 \mathrm{~mm}$ spot beam, $15 \mathrm{~ns}$ pulse duration, $10 \mathrm{~Hz}$ pulse frequency). The laser fluence, expressed as an energy per unit area of the beam, ranged from 200 to $400 \mathrm{~mJ} / \mathrm{cm}_{2}$. The irradiation conditions have been adjusted by an experienced restorer to optimize the cleaning result. The surface of the samples was sprayed with water just before irradiation. Around a quarter of each sample was preserved from laser cleaning and kept as a reference area (Area 1 in Fig. 1). A complementary laser cleaning was carried out in the same conditions in order to collect the ablated particles during laser irradiation. In this case, the sample was inclined at $45^{\circ}$ in a box and small metal grids used for transmission electronic microscope observation were held close to it during the cleaning operation.

3.3 UV-B exposure: After laser cleaning, the plates were exposed to UV-B radiation (313 nm) in an accelerated UV degradation chamber (Q-Panel LAB product) following previously optimized conditions [8]: 90 hours at an irradiance of $1.42 \mathrm{~W} / \mathrm{m}_{2}$ reaching a total UV-B fluence of $46 \mathrm{~J} / \mathrm{cm} 2$. A second quarter of the sample was protected with an aluminum foil to preserve the yellowed surface obtained after laser cleaning (Area 2 in Fig. 1). The UV-B exposed surface represents the rest of the sample (Area 3 in Fig. 1).

3.4 Spectrocolorimetry: Color measurements were carried out with a Hunterlab MiniScan XE Plus System spectrocolorimeter with illuminant D65 using the $10^{\circ}$ observer, equipped with a hand-held positioning device [8], to evaluate the color variations after QS laser cleaning (Area 2 in Fig. 1) and UVB exposure versus time (Area 3 in Fig. 1). The evolution of the $b^{*}$ parameter, representative of the chromaticity of interest, was specifically followed with respect to the gypsum reference surface. 

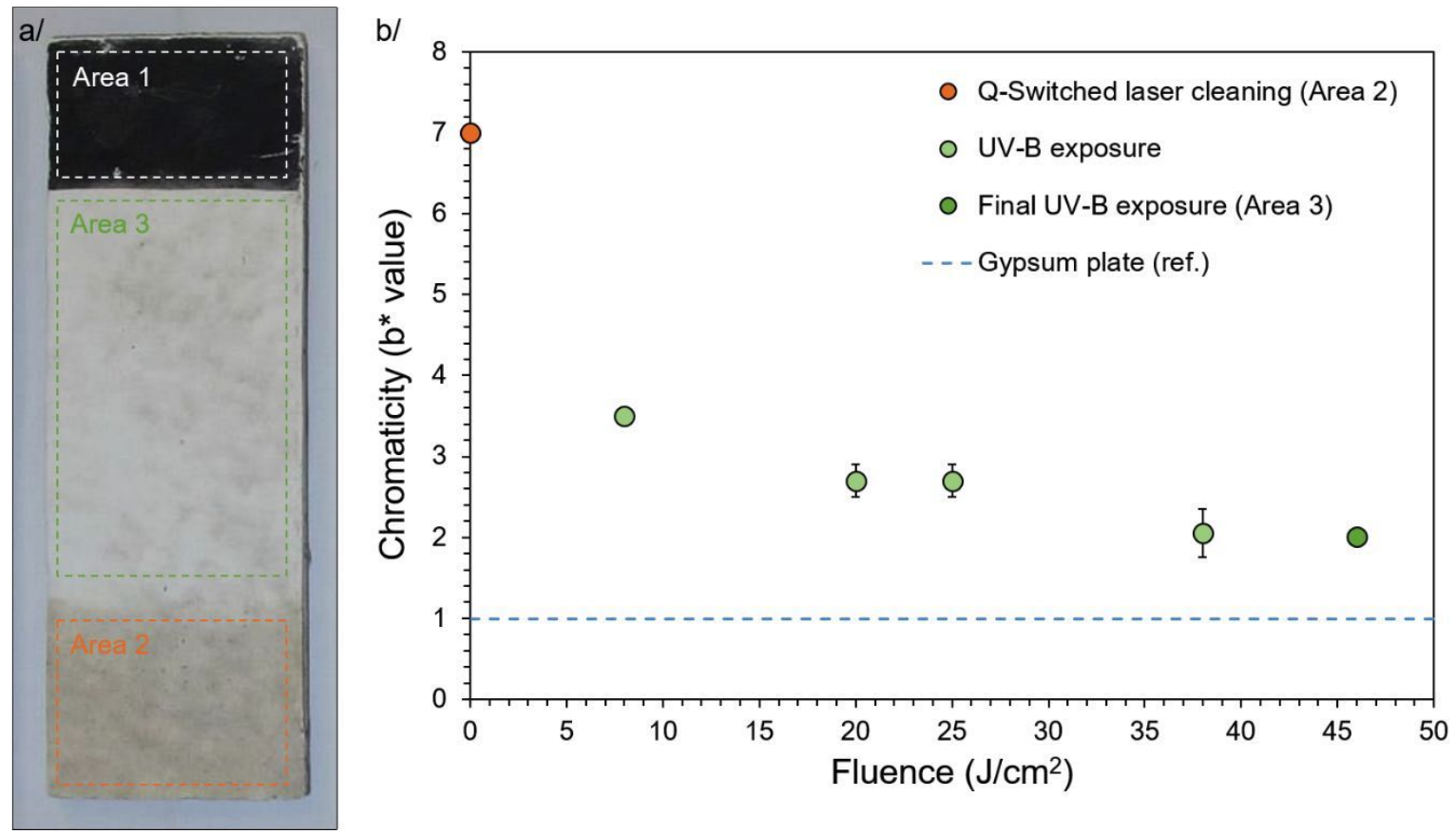

Figure 1. a/ Macroscopic color changes of a gypsum plate covered with lamp black (Area 1) after QSwitched laser cleaning (Area 2) and UV-B exposure (Area 3). The plate is $7.5 \mathrm{~cm}$ long. b/ Chromatic evolution of the Q-Switched laser cleaned area ( $b^{*}$ value) as function of the cumulated UV-B fluence. The dashed blue line corresponds to the $b^{*}$ value measured on the reverse side of the gypsum plate. 3.5 X-ray photoelectron spectroscopy: XPS was recorded on Areas 1-3 to characterize the elemental composition and the chemical speciation of the surface species. Reference spectra were also acquired on a bare gypsum plate and on the lamp black powder for comparison purposes. The experiments were performed under ultra-high vacuum using a Resolve 120 hemispherical electron analyzer (PSP Vacuum) and a TX400 (PSP vacuum) unmonochromatized X-ray source (Mg Ka at $1253.6 \mathrm{eV}$ ) operated at $100 \mathrm{~W}$. The information depth of XPS at this excitation energy and in the geometrical arrangement of the setup is typically $1 \mathrm{~nm}$ at the $\mathrm{C} 1 \mathrm{~s}$ line. Survey spectra were first collected at pass energy of $50 \mathrm{eV}$ and an energy step of $0.2 \mathrm{eV}$, while the $\mathrm{C} 1 \mathrm{~s}$ lines were collected at $20 \mathrm{eV}$ pass energy, and a step of $0.1 \mathrm{eV}$. The XPS lines were deconvoluted with the CasaXPS program, using Gaussian/Lorentzian profiles and after Shirley-type background subtraction. Elemental composition (in at. \%) are obtained from the analysis of the survey spectra and after correction by the relative sensitivity factors provided in the program. total reflectance (ATR, germanium crystal) mode using a Bruker VERTEX70 mid-IR Fourier Transform 
155

156

157

158

159

160

161

162

163

164

165

166

167

168

169

170

171

172

173

174

175

176

177

178

179

180

181

spectrometer equipped with a temperature-stabilized DLaTGS detector. All spectra were accumulated on the surface of the different areas as well as the reference materials (bare gypsum plaster and lamp black) in a spectral range of $650-4000 \mathrm{~cm}^{-1}$ by recording 200 scans at a resolution of $4 \mathrm{~cm}^{-1}$. In this energy domain, information depth in ATR is in the range of 0.2-1.4 $\mu \mathrm{m}$ for gypsum, i.e. 200-1400 times deeper than XPS. The Opus software was used for the baseline correction, where a polynomial fit was applied over the whole spectral range with a minimal number of anchor points (between 3 and 5, typically). The characterization of the absorbance bands and the interpretation of their evolution with the different treatments were carried out by a curve fitting procedure using the PeakFit software. We have selected two regions of interests (ROIs) where specific spectral features of carbon are observed, corresponding to the intervals between 1300 and $1600 \mathrm{~cm}^{-1}$ and between 2800 and $3100 \mathrm{~cm}^{-1}$. The ROIs were adjusted with several absorbance bands with Voigt profiles. Such profile is common in complex condensed materials and corresponds to a convolution of Lorentzian and Gaussian profiles. The fitting was achieved using a least-squares iterative procedure by varying the peak position, amplitude/area, Gaussian and Lorentzian half-widths for all absorbance bands.

3.7 Scanning electron microscopy and transmission electron microscopy: SEM was used to study the morphology of the lamp black particles, the gypsum plaster substrate, and the treated areas at a micron and sub-micron scale. The SEM observations were performed with a JEOL 6320F operated at $15 \mathrm{kV}$. Samples were coated with titanium prior to being placed in the SEM chamber. TEM was performed to characterize the nanoscale morphology and internal structure of the particles composing the lamp black and the ablated particles collected on the grids during cleaning tests. TEM observations were carried out on a JEOL JEM 2011 operated at 200kV. Bright field TEM micrographs were acquired with a CCD camera (GATAN, Ultrascan ${ }^{\circledR}$ 1000XP) assisted by the Digital Micrograph software (GATAN).

\section{Results}

Visual observation (Fig. 1a) allows an easy distinction of the three different areas (Area 1/lamp black crust, Area 2/after Q-Switched laser cleaning, and Area 3/after 90 hours of UV-B exposure). After 
laser cleaning, Area 2 has a yellowish aspect, with a $b^{*}$ value of about 7 in term of chromaticity. It corresponds to the $b^{*}$ value at zero UV-B fluence (Fig. $1 b$ ). The evolution of $b^{*}$ indicates the colorimetric changes induced by UV-B exposure of Area 3. Colorimetric measurements were made repetitively on this area after $15,40,50,70$, and 90 hours of exposure. The decrease of $b^{*}$ highlights the progressive de-yellowing phenomenon previously described $[8,11]$. However, $b^{*}$ does not reach the reference value of 0.99 (dashed line in Fig. 1b) within the considered exposure time, indicating that UVB exposure does not fully reveal the original color of the gypsum plate.

The deconvoluted C1s XPS spectra recorded on Areas 1-3 are shown in Fig. 2a (the C1s and O1s spectra, including those of the bare gypsum plate and the lamp black particles are presented and further discussed in the supplementary material S1). The black crust of Area 1 (Fig. 2a, bottom) presents a main peak located at a binding energy of $284.8 \mathrm{eV}$ corresponding to the lamp black particles, and typical of graphitic materials [13]. The second peak at $288.2 \mathrm{eV}$ is related to carbonate $\mathrm{CO}_{3}$, likely in the form of calcium carbonate $\mathrm{CaCO}_{3}[14]$ contaminating the gypsum plate surface, a contamination of unknown origin. It is already present on the bare gypsum spectrum (see supplementary material S1) and is detected in Area 1 as the substrate is not perfectly covered by the carbon crust (see below, SEM results, Fig.5a). The lamp black peak contributes to 49 at. \% to the elemental surface composition of Area 1 (Fig. $2 b$ ). After laser cleaning (Area 2) the carbonate peak at $288.2 \mathrm{eV}$ has increased relatively to the other contributions (Fig. 2a, middle). The residual carbon peak, now shifted at $285.5 \mathrm{eV}$, represents only 4 at. $\%$ of the elemental composition of Area 2 (Fig. $2 \mathrm{~b}$ ). This $+0.7 \mathrm{eV}$ shift indicates that this residual carbon is not of the same kind than the initial lamp black particles. Binding energies of $285.5 \mathrm{eV}$ correspond to aliphatic hydrocarbons [15], which therefore dominate the composition of the residual carbon layer. A further $\mathrm{C} 1 \mathrm{~s}$ peak at $291.6 \mathrm{eV}$ appears, typical of $\mathrm{CO}_{2}[16]$. We assume that a part of the $\mathrm{CaCO}_{3}$ species located at the very surface (typically $1 \mathrm{~nm}$ in depth) have been decomposed in $\mathrm{CaO}+\mathrm{CO}_{2}$ [17] under the laser beam. $\mathrm{CO}_{2}$ remains trapped in the subsurface region, perhaps through chemical complexation or in nano-bubbles. As this reaction takes place at $\mathrm{T}^{\circ}>800^{\circ} \mathrm{C}$, it allows setting at $800{ }^{\circ} \mathrm{C}$ the lower temperature experienced by the first atomic layers of the gypsum surface during the laser treatment. 
After UV-B exposure (Area 3, Fig. 2a top), the residual carbon peak at $285.5 \mathrm{eV}$ has almost totally

209 disappeared. The remaining signal represents only $0.75 \pm 0.15$ at. \% (rounded at 1 at. \% Fig. $2 b$ ) of the elemental composition of Area 3 (Fig. 2b), while the $\mathrm{CaCO}_{3}$ and the $\mathrm{CO}_{2}$ peaks are still present. UV-B induces the removal of the residual carbon compounds, which eventually whitens the gypsum surface $[8,11]$. We suppose that this 1 at. \% of remaining carbon precludes the full recovery of the original chromaticity of the gypsum plate (Fig. 1b).

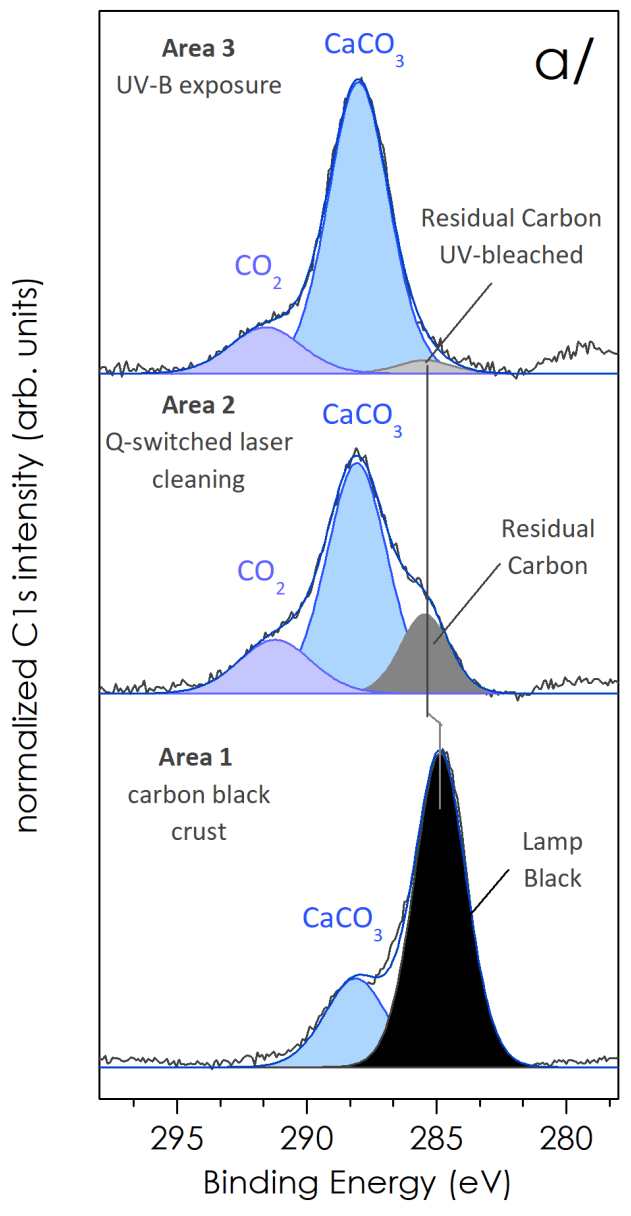

Figure 2. a/ Deconvoluted C1s XPS lines of Areas 1-3. b/ Contributions to the total surface composition (in at. \%) of the lamp black (LB) C1s line in Area 1, and of the residual carbon $(\mathrm{RC}) \mathrm{C} 1 \mathrm{~s}$ lines in Area 2 and 3.

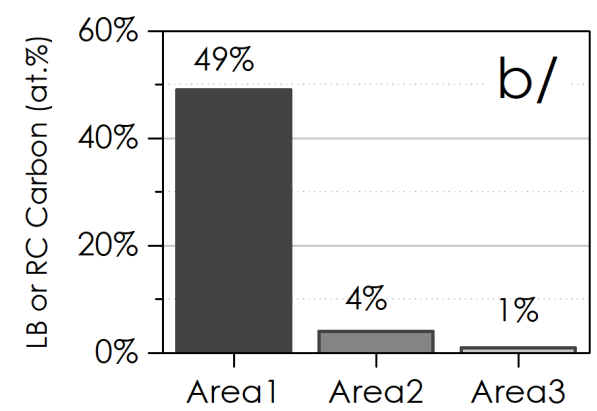

The FTIR spectra of the gypsum substrate and those of Areas 1-3 are displayed in Fig. 3, after baseline subtraction and normalization by their integrated area. The most intense absorption bands come from the bending $(\delta)$ and stretching $(v)$ vibration of gypsum, located at $1010\left(\mathrm{v}_{1} \mathrm{SO}_{4}\right), 1150\left(\mathrm{U}_{3} \mathrm{SO}_{4}\right), 1620$ 
$217(\delta \mathrm{O}-\mathrm{H} \cdot \mathrm{O}), 1680(\delta \mathrm{O}-\mathrm{H} \cdot \cdot \mathrm{O}), 3240(\mathrm{v} \mathrm{O}-\mathrm{H} \cdot \mathrm{O}), 3410(\mathrm{v} \mathrm{O}-\mathrm{H} \cdot \mathrm{O})$, and $3550 \mathrm{~cm}^{-1}(\mathrm{v} \mathrm{O}-\mathrm{H} \cdot \mathrm{O})[18]$.

218 Very weak bands coming from $\mathrm{CH}$ and $\mathrm{CC}$ vibrations are also present but barely distinguishable on Fig.

2193

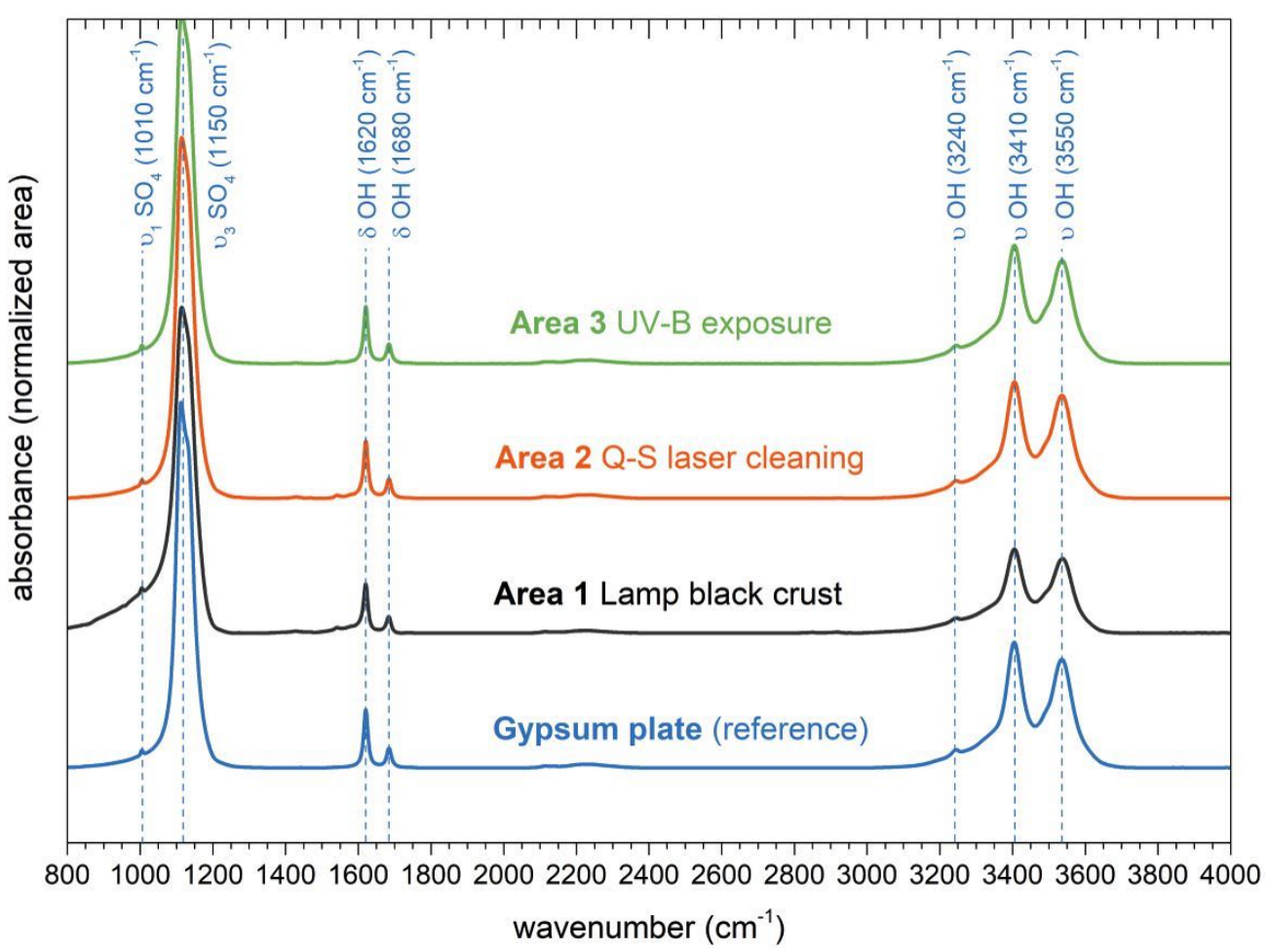

Figure 3. Baseline corrected ATR-FTIR spectra obtained on the reference gypsum plate and areas 1-3.

The $\mathrm{CH}$ and $\mathrm{CC}$ vibrations can be studied on the two ROIs $\left(1300-1600 \mathrm{~cm}^{-1}\right.$ and $2800-3100 \mathrm{~cm}^{-}$

$\left.{ }^{1}\right)$ presented Fig. $4 \mathrm{a}$ and $4 \mathrm{~b}$ where the spectral intensities have been renormalized to the gypsum bands at $1680 \mathrm{~cm}^{-1}$ (Fig. 4a) and $3410 \mathrm{~cm}^{-1}$ (Fig. 4b). In the 1300-1600 $\mathrm{cm}^{-1}$ region (Fig. 4a), these bands are assigned to the $\mathrm{C}-\mathrm{H}$ bending bands of aliphatic compounds $\left(\delta \mathrm{CH}_{3} \mathrm{sym} . \sim 1390 \mathrm{~cm}^{-1} ; \delta \mathrm{CH}_{2} \sim 1430 \mathrm{~cm}^{-}\right.$ ${ }^{1} ; \delta \mathrm{CH}_{3}$ asym. $\left.\sim 1470 \mathrm{~cm}^{-1}\right)$ and to the stretching bands of aromatic rings $\left(v \mathrm{C}=\mathrm{C} \sim 1540\right.$ and $1600 \mathrm{~cm}^{-}$ $\left.{ }^{1}\right)$ [19]. In the $2800-3100 \mathrm{~cm}^{-1}$ region (Fig. 4b), the absorption bands are assigned to the $\mathrm{C}-\mathrm{H}$ stretching bands of aliphatic and aromatic compounds $\left(v \mathrm{CH}_{2}\right.$ bridges $\sim 2825 \mathrm{~cm}^{-1} ; v \mathrm{CH}_{2} \mathrm{sym} . \sim 2850 \mathrm{~cm}^{-1} ; v \mathrm{CH}_{3}$ sym. $\sim 2875 \mathrm{~cm}^{-1} v \mathrm{CH} \sim 2895 \mathrm{~cm}^{-1} ; v \mathrm{CH}_{2}$ asym. $\sim 2920 \mathrm{~cm}^{-1} ; v \mathrm{CH}_{3}$ asym. $\sim 2960 \mathrm{~cm}^{-1}, v \mathrm{CH}$ aromatic at $\left.3030 \mathrm{~cm}^{-1}\right)[19,20]$. These organic compounds are present in the lamp black particles, made of a mixture of small bent graphitic crystallites (see below, TEM results) and matrix-bonded hydrocarbons. Assuming that the substrate bands remain unaltered by the different treatments on the depth probed by the ATR technique, the normalization allows estimating the relative changes in the carbon coverages 
with the different treatments. A spectral deconvolution of the FTIR signal is therefore presented in Fig.

2334 for the two ROIs.
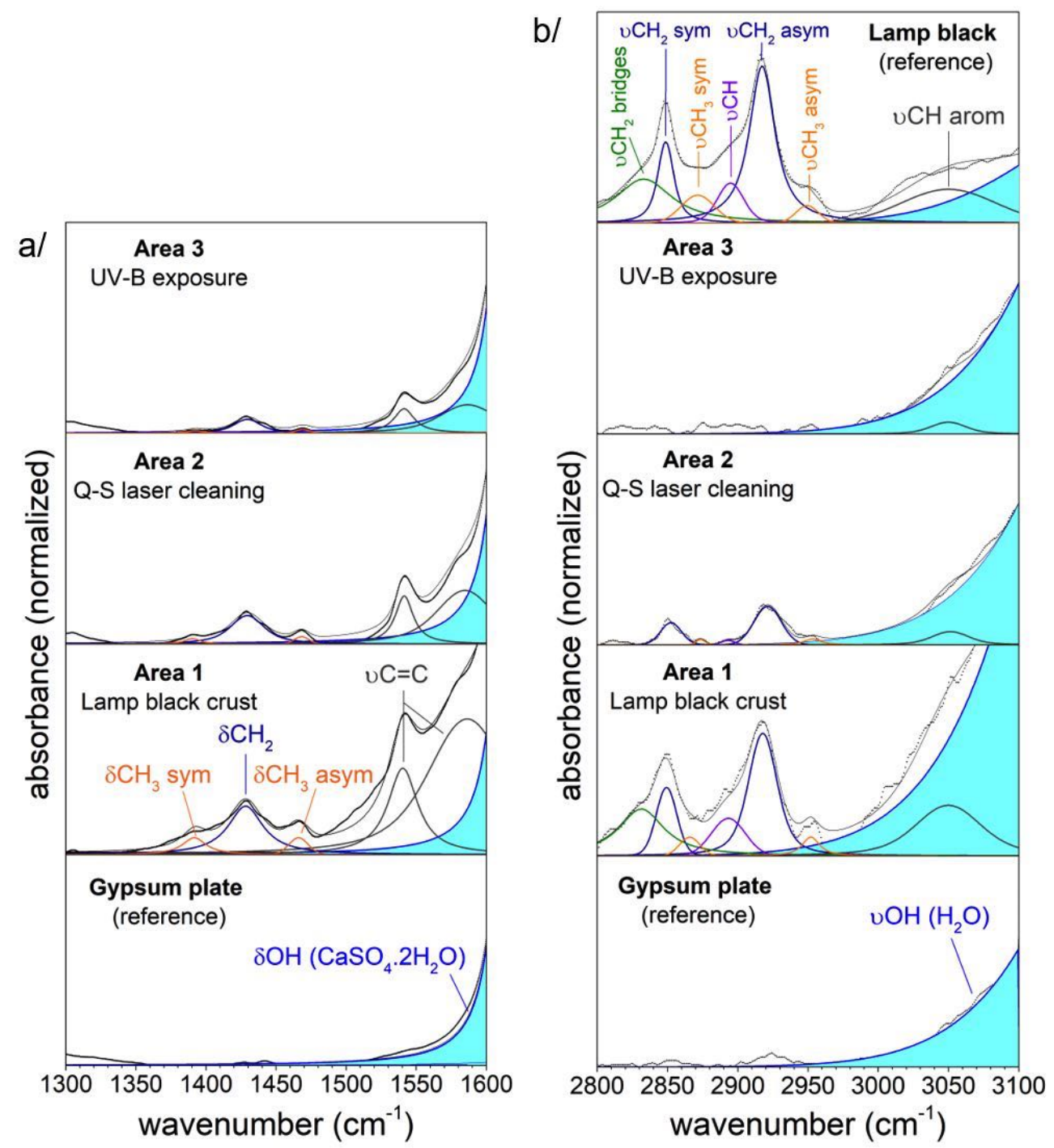

Figure 4. Contribution of the different vibrational modes on the curve fitting analysis of regions a/ $1300-1600 \mathrm{~cm}^{-1}$ and $\mathrm{b} / 2800-3100 \mathrm{~cm}^{-1}$. The reference spectrum of the lamp black powder was also fitted in the $2800-3100 \mathrm{~cm}^{-1}$ domain for comparison.

In Area 1 the prevalence of the two absorption bands at 2850 and $2925 \mathrm{~cm}^{-1}\left(\mathrm{CH}_{2}\right.$ symmetric

and asymmetric stretching modes, in blue lines on Fig. $4 \mathrm{~b}$ ) with respect to those of the $\mathrm{CH}_{3}$ groups terminating the aliphatic chains (in orange lines) indicates that these chains are long. The band at 2895 $\mathrm{cm}^{-1}$ (in purple line on Fig. $4 \mathrm{~b}$ ) is related to $\mathrm{C}-\mathrm{H}$ stretching of tertiary carbon atom at branching points of the aliphatic chains [20]. The absorption band at $2825 \mathrm{~cm}^{-1}$ is assigned to $\mathrm{CH}_{2}$ groups located near sp2-hybridized carbon (in green on Fig. 4b), for instance in aliphatic species bonded to (or binding) the edge(s) of the graphitic crystallites [20]. This band is not detected anymore in the spectrum of Area 2, indicating that these peripheral $\mathrm{CH}_{2}$ groups have disappeared after the laser impact. This is a further 
242 evidence, with XPS, that the structure of the residual carbon compounds is different from the initial

243 lamp black particles. Yet, the C-H stretching bands of aliphatic chains (2850 and $\left.2925 \mathrm{~cm}^{-1}\right)$, the 244 stretching bands of aromatic rings $\left(v \mathrm{C}=\mathrm{C} \sim 1540\right.$ and $\left.1600 \mathrm{~cm}^{-1}\right)$, and aromatic $\mathrm{C}-\mathrm{H}$ stretching $(v \mathrm{CH}$ 245 aromatic at $3030 \mathrm{~cm}^{-1}$ ) are still observed, with a different intensity balance. If the residual carbon 246 compounds are dominated by aliphatic species, they also contain aromatic hydrocarbons. The layer of organic carbon after laser cleaning is also thinner, since all the infrared bands have strongly decreased in intensity. Molecular organic compounds were also identified recently by Papanikolaou et al. [21]

249 through their fluorescence contribution to the Raman signal of laser-cleaned marbles. These compounds are eventually bleached upon UV-B exposure, as barely no corresponding absorbance bands are detected in Area 3 (Fig. 4b). They are likely below the detection limit, as some remaining signal of the corresponding C-H groups is observed in the $1300-1600 \mathrm{~cm}^{-1}$ region of Area 3 (Fig. 4a). In this spectral region, a decrease of the infrared signal is also observed with the treatments, but less markedly than in the $\mathrm{C}-\mathrm{H}$ stretching region.

The SEM observation of Area 1 reveals that the gypsum plate is made of a mixture of prismatic, lamellar to acicular crystals with sharp edges entangled together (Fig. 5a). The lamp black particles lie on the crystals and consist of aggregates of submicronic spherical particles (Fig. 5a and b). Some parts of the substrate remain uncovered, as already inferred from the XPS data (Fig. 2a, Area 1). On the laser cleaned surface (Area 2), the same mixture of prismatic, lamellar and acicular gypsum crystals is observed (Fig. 5c), but the lamp black aggregates have disappeared. Single submicronic round particles are sometimes detected (Fig. 5d, arrow), in rare places where the surface of the gypsum crystals is altered. This occurs probably when the crystals are not covered with lamp black particles, and consequently absorb all the laser energy. 

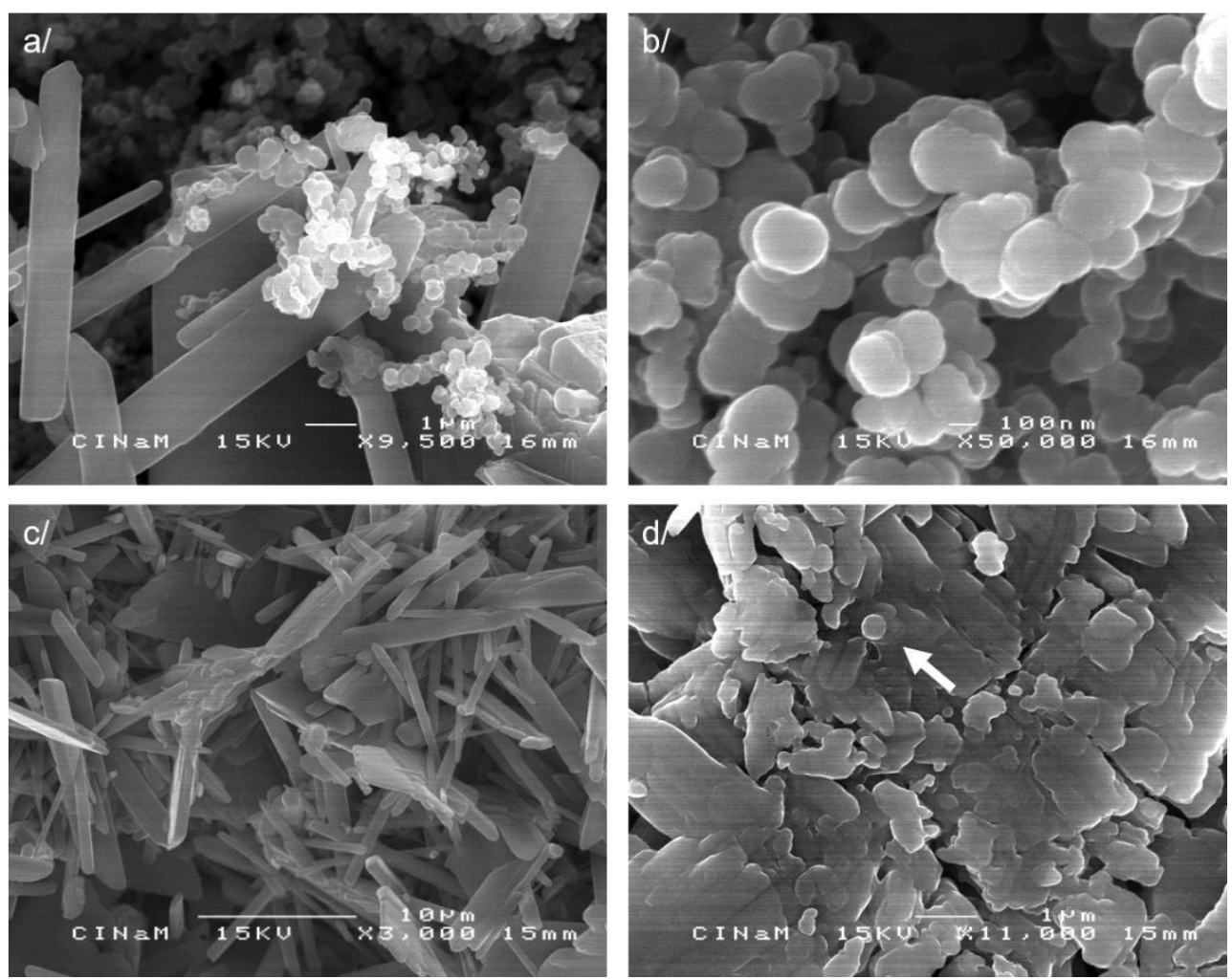

Figure 5. SEM micrographs of gypsum covered with lamp black before (Area 1) and after Q-S laser cleaning (Area 2) obtained in secondary electron mode. a/ Surface of the plaster plate showing gypsum crystals covered with aggregates of lamp black particles (Area 1). b/ Aggregates of lamp black particles of spherical shapes (Area 1). c/ Surface of the plate after Q-S laser cleaning (Area 2). $\mathrm{d} /$ Details of the gypsum crystal where some alterations are observed (Area 2).

TEM micrographs show that the lamp black particles consist of primary spherical nanoparticles arranged in aggregates (Fig. 6a). The diameter of the primary nanoparticles ranges from 50 to $200 \mathrm{~nm}$

(Fig. 6a and b). Higher magnification (Fig. 6c) reveals their inner structure: the dark fringes correspond to small bent graphitic layers, concentrically arranged in an onion-like structure typical of soot particles [22]. After laser treatment the ejected particles have been also analyzed at high magnification. Some of them retain this initial structure (Fig. 6d), but new kinds of particles are observed. Figs. 6e-f show a class of particles with concentric multifaceted stacks of graphitic layers (white arrow on Fig. 6f) wrapping voids. A second type of particles displays evidences of a partial destruction (Fig. 6g), where graphitic stacks (Fig. 6h and i, white arrow) coexist with an amorphous carbon phase (Fig. 6g, black arrow), and where the concentric organization is lost. These images correspond well to the observed structural and chemical changes of carbon nanoparticles upon laser annealing [23,24], which simultaneously induces the crystallization of a part of the particles and the vaporization of another part, 

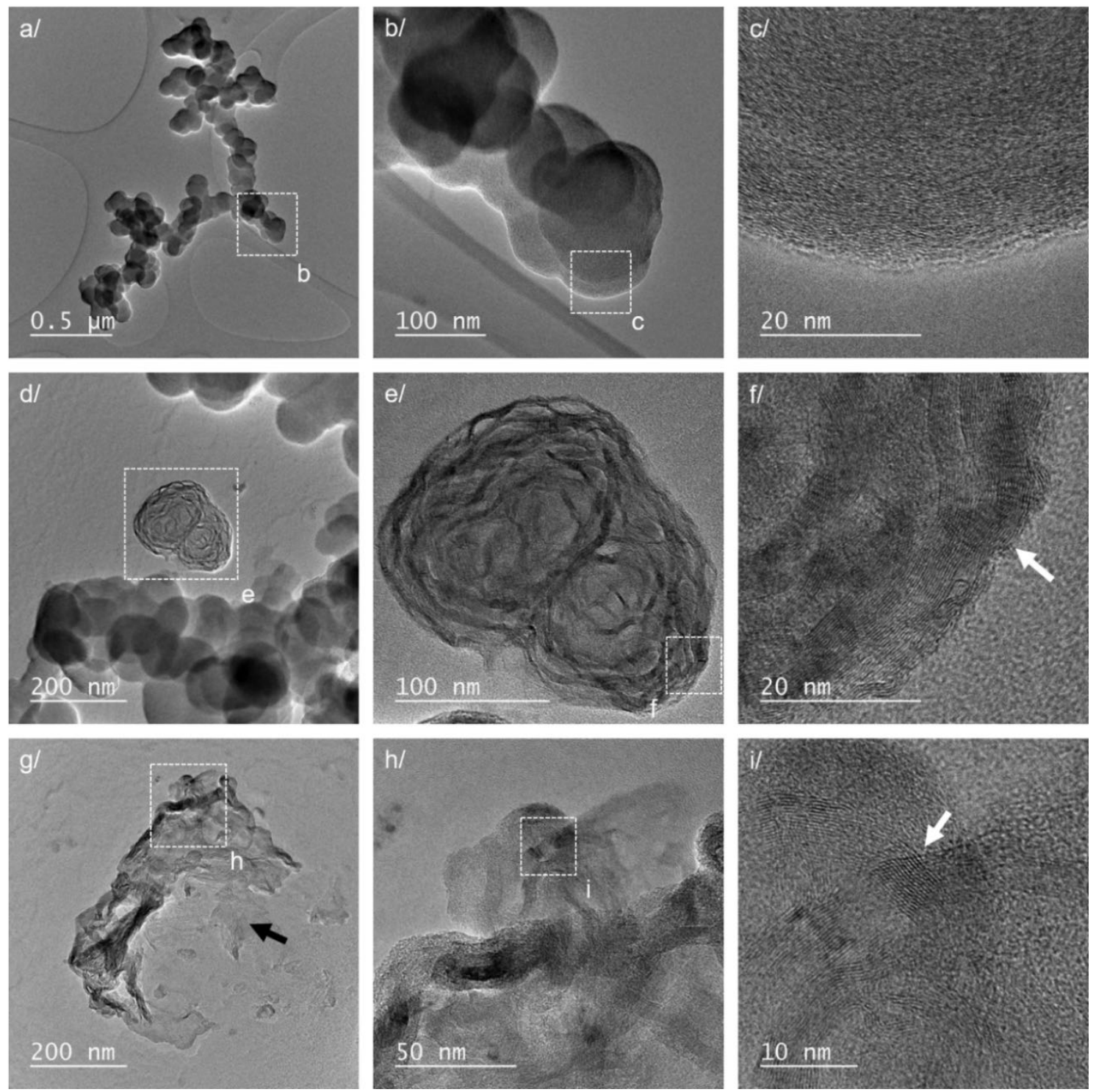

Figure 6. Structural reorganization of the lamp black particles. Bright field TEM micrographs of the lamp black particles before (a to c) and after Q-S laser cleaning (d to i). a/ to c/ aggregate composed of spherical nanoparticles, made of small graphitic planes (dark fringes) concentrically arranged. $d /$ to $f /$ aggregate of particles after laser irradiation showing alternating graphitic stacks (white arrow) and voids. $\mathrm{g} /$ to $\mathrm{i} /$ ablated particles with elongated and/or folded ribbon structures (white arrow) mixed with an amorphous carbon phase (black arrow).

\section{Discussion}

The TEM observations of the ejected particles indicate that the lamp black aggregates have been processed at very high temperatures under the laser beam. Indeed, since the thermal diffusion length is 
$289(4 \mathrm{D} \tau)^{1 / 2}$ where $\mathrm{D}$ is the thermal diffusivity of the material and the laser pulse duration [25], the energy 290 of short laser pulses is mainly absorbed in a small thickness [2]. As reported by Abrahamson et al. [23], 291 annealed particles like those of Fig. 6e readily form after a single pulse at $50 \mathrm{~mJ} / \mathrm{cm}^{2}$ of a same Nd:YAG 292 Q-switched laser at $1064 \mathrm{~nm}$, corresponding to an equivalent temperature of $2850^{\circ} \mathrm{C}$. This induces the stacking, the growth and the de-winkling of the graphitic planes [26], accompanied by the increase of the graphitic character of the considered particles [24]. At increased number of pulses, Abrahamson et al. measured a maximum temperature of $4180^{\circ} \mathrm{C}\left(>4\right.$ pulses or $\left.300 \mathrm{~mJ} / \mathrm{cm}^{2}\right)$ and starts detecting $\mathrm{C}_{2}$ (ethene) and $\mathrm{C}_{3}$ (propadiene) radicals in the incandescence signal of the laser plume. However, carbon vaporization already starts below 4 pulses $\left(\right.$ at $3500^{\circ} \mathrm{C}$ ), as the authors observed solidified carbon material formed by nucleation of vaporized carbon [24]. In our case, laser cleaning is achieved at pulse frequency $(10 \mathrm{~Hz})$ and fluence $\left(200-400 \mathrm{~mJ} / \mathrm{cm}^{2}\right)$ conditions where both graphitization and vaporization occur. This leads to various forms of the ejected carbon particles observed by TEM: multifaceted annealed particles (Fig. 6e), partially annealed unstructured particles mixed with an amorphous carbon phase (Fig. $6 \mathrm{~g}$ ), and finally intact particles (Fig 6b).

On the substrate side, we have seen that within the $1 \mathrm{~nm}$ in depth probed by XPS, the laser treatment has increased the surface temperature to a minimum of $800^{\circ} \mathrm{C}$, as indicated by the decomposition of calcite (Fig. 2). At such temperature, dehydration of the surface of gypsum crystals certainly occurs, as this process starts around $120^{\circ} \mathrm{C}$. Yet, the Ca $2 \mathrm{p}$ line (not shown) remains unchanged after the laser treatment. In particular, no $\mathrm{CaO}$ species are detected, and therefore anhydrous gypsum has not thermally decomposed into $\mathrm{CaO}+\mathrm{SO}_{2}+1 / 2 \mathrm{O}_{2}$ [27]. Since this reaction starts around $1200^{\circ} \mathrm{C}$, it allows estimating the maximum surface temperature at $1200^{\circ} \mathrm{C}$. Note however that the melting point of $\mathrm{CaSO}_{4}$ is not far above, at $1460^{\circ} \mathrm{C}$. If the surface temperature gets close to $1460^{\circ} \mathrm{C}$ at some places, it is not surprising to observe some altered gypsum crystals and round particles (Fig. 5d) resulting from the (partial) melting of gypsum. However, since the gypsum bands in the infrared spectra remain unchanged (Fig. 3) upon the laser treatment, no thermal alteration of the bulk of the gypsum substrate has occurred. This is consistent with the limited thermal diffusion length of the laser pulse into the substrate $(28 \mathrm{~nm})$. 
The SEM observations clearly indicate that no lamp black aggregates remain after laser cleaning. Therefore, the residual carbon results from the deposition of volatile carbon species at the surface of the gypsum substrate. At the laser impact, the lamp black particles explode, are vaporized, chemical bonds are broken, producing a plasma mixing atoms, molecules, and ions, where gas-phase chemical reactions occur. A fraction of the formed products can condense on the gypsum substrate. The resulting organic compounds are not visible by SEM, but they yellow the substrate. FTIR and XPS indicate that the residual carbon is made of hydrocarbon dominated by aliphatic species, mixed with few aromatic species. Their organic nature is essential for the facile degradation by UV-B radiation, through photooxidation of linear or cyclic aliphatic [28] and aromatic hydrocarbons [29], that would not take place if they were highly graphitic or made of residual black lamp particles [30]. Literature indicates that laser ablation/vaporization of carbon particles produces small gas-phase carbon clusters [31] at $\mathrm{T}^{\circ}<3500^{\circ} \mathrm{C}$, and carbenes $\mathrm{C}_{2}$ and $\mathrm{C}_{3}$ at $\mathrm{T}>4180^{\circ} \mathrm{C}$ (and this is probably not limited to these species) [24]. In any case, the formation of hydrocarbons requires both the catenation (polymerization) of carbene - a facile reaction-, and a further hydrogen addition to the formed carbon chains. Hydrogen is provided by the laser dissociation of water molecules coming both from dehydration of the gypsum surface and from the water sprayed by the operator before the laser cleaning. Indeed, in presence of nanoparticles, water radiolysis and breakdown are caused by the secondary electrons flux generated by the visible/IR laser irradiations $[32,33]$. Water dissociation also provides $\mathrm{O}$ and $\mathrm{OH}$ radicals allowing for oxidation and hydroxylation of the carbon precursors. Since the residual carbon compounds yellow the surface, they include specific species not absorbing in the 560-590 nm wavelength range. A possible candidate is the carbonyl group $-\mathrm{C}=\mathrm{O}$, which causes the yellowing of organic polymers [34]. Similar to the hydrogenation reactions, $-\mathrm{C}=\mathrm{O}$ groups can form by oxidation of the carbon precursors. Their probable low concentration makes them difficult to detect with infrared spectroscopy, and, furthermore, their typical bands (1670-1820 $\left.\mathrm{cm}^{-1}\right)$ are hidden by the bending $\mathrm{OH}$ vibrations of the gypsum substrate. XPS would be more sensitive, but the $\mathrm{C}=\mathrm{O}$ groups also lie close in energy to the $\mathrm{CO}_{3}$ group of the calcium carbonate, making their detection difficult. 
This study evidences, on a model system, the contribution of hydrocarbons stemming from the

342 laser annealing of the lamp black particles. In the actual conditions of black crust soiling artworks, this

343

344

345

346 process will add to the other causes of yellowing reported in the literature so far, such as the diffusion of soluble organic compounds [5,35], and the chemical transformations of iron oxides [12].

\section{Summary and conclusions}

Black crust frequently covers stones and plaster of artworks in urban environments. The Nd:YAG Q-Switched laser cleaning of the soiled surfaces at $1064 \mathrm{~nm}$ induces however a noticeable yellowing. While this phenomenon is now mitigated by the simultaneous [21] or consecutive use of UV-B $[8,11]$, the nature of the yellowing compounds remains unknown. The present study shows, on a model system, that the initial lamp black crust is composed of aggregates of graphitic spherical nanoparticles with matrix-bonded organic species. The Nd:YAG Q-Switched laser provokes the ablation/vaporization of these particles. Some of the ejected particles seem intact, others show signs of annealing at very high temperature, such as partial graphitization or partial destruction accompanied by amorphization. A part of the laser energy is transferred to the top surface of the gypsum substrate, causing the dissociation of the calcium carbonate contaminating the substrate, within a depth of $1 \mathrm{~nm}$ probed by XPS. The laser ablation of the carbon nanoparticles produces a plasma plume where carbon species can polymerize and react with hydrogen and oxygen produced by the dissociation of water, emitted by both the gypsum surface and spread by the operator. This leads to the formation of hydrocarbon chains and few aromatic species which redeposit on the substrate. The yellow color could be due to the presence of some carbonyl groups $(\mathrm{C}=\mathrm{O})$ attached to the polymeric chains. The organic nature of this residual carbon allows for its facile photooxidation under the subsequent UV-B exposure.

In the light of these results, could laser cleaning be improved? The fluence and frequency of the laser pulse are set just at the ablation threshold to allow for the removal of the particles. Yet, their vaporization occurs despite this minimum deposited energy. The water sprayed before cleaning strongly enhances the process [25], but hydrogen and oxygen radicals provided by water favor the conversion of 
367

368

369

370

371

372

373

374

375

376

377

378

379

380

381

382

383

vaporized carbon into hydrocarbon species, and their oxidation is at the origin of the yellow color. Even at $25^{\circ} \mathrm{C}$ and a typical $40 \%$ relative humidity, the partial pressure of atmospheric water (9.6 Torr) might provide enough water molecules (3.1 1017 molecules.cm-3) for these reactions to occur if no water is sprayed by the operator. From all these considerations, avoiding the formation of such a yellowish residual hydrocarbon film after laser cleaning seems rather difficult. It makes the subsequent UV-B exposure mandatory $[8,11,21]$.

\section{Acknowledgments}

The authors would like to thank Cecile de Oliveira and Veronique Vergès-Belmin (LRMH-USR 3224, Champs-sur-Marne, France) for their help and careful advices, and Agata Dmochowska-Brasseur (Ateliers Bouvier, Les Angles, France) for the laser cleaning of the studied samples.

\section{References}

[1] S. Siano, R. Salimbeni, Advances in Laser cleaning of artwork and objects of historical interest: the optimized pulse duration approach, Acc. Chem. Res. 43 (2010) 739-750.

[2] S. Siano, J. Agresti, I. Cacciari, D. Ciofini, M. Mascalchi, I. Osticioli, A. A. Mencaglia, laser cleaning in conservation of stone, metal, and painted artifacts: state of the art and new insights on the use of the Nd:YAG lasers, Appl. Phys. A 106 (2012) 419-446.

[3] P. Bromblet, M. Labouré, G. Orial, Diversity of the cleaning procedures including laser for the restoration of carved portals in France over the last ten years, Journal of Cultural Heritage 4 (2003) $17 \mathrm{~s}-26 \mathrm{~s}$

[4] J. Delivré, Laser cleaning: is there specific laser esthetics?, Journal of Cultural Heritage 4 (2003) 245-248.

[5] M. Gavino, B. Hermosin, V. Vergès-Belmin, W. Nowik, C. Saiz-Jimenez, New insights on the chemical nature of stone yellowing produced after laser cleaning, Cultural Heritage Conservation 
and Environmental Impact Assessments by Non-Destructive Testing and Micro-Analysis, eds. Van Grieken and Janssens, Taylor \& Francis Group, London (2005) 149-157.

[6] V. Vergès-Belmin, C. Dignard, Laser yellowing, myth or reality?, Journal of Cultural Heritage 4 (2003) 238-244.

[7] V. Vergès-Belmin, M. Labouré, Poultices as a way to eliminate the yellowing effect linked to limestone laser cleaning, Lasers in the Conservation of Artworks: LACONA VI Proceedings, Vienna, Austria 21-25 september 2005, eds. J. Nimmrichter, W. Kautek and M. Schreiner, New York Springer, (2005) 115-124.

[8] C. De Oliveira, P. Bromblet, A. Colombini, V. Vergès-Belmin, Medium-wave ultraviolet radiation to eliminate laser-induced yellowing generated by the laser removal of lamp black on gypsum, Studies in Conservation 60 (2015), S34-S40.

[9] C. De Oliveira, V. Vergès-Belmin, D. Demaille, P. Bromblet, Lamp black and hematite contribution to laser yellowing: a study on technical gypsum samples, Studies in Conservation 61 (2015), 136145.

[10] M.F. La Russa, C.M. Belfiore, V. Comite, D. Barca, A. Bonnazza, S.A. Ruffolo, G.M. Crisci, A. Pezzino, Geochemical study of black crusts as a diagnostic tool in cultural heritage, Appl Phys A 113 (2013), 1151-1162.

[11] M. Godet, V. Vergès-Belmin, P. Bromblet, A. Colombini, M. Saheb, C. Andraud, Fly-ash contribution to Nd:YAG laser yellowing and its mitigation using UV-B light, Journal of Cultural Heritage 29 (2018), 36-42.

[12] M. Godet, V. Vergès-Belmin, N. Gauquelin, M. Saheb, J. Monnier, E. Leroy, J. Bourgon, J. Verbeeck, C. Andraud, Nanoscale investigation by TEM and STEM-EELS of the laser induced yellowing, Micron 115 (2018), 25-31.

[13] B.J. Bachman, M.J. Vasile, Ion bombardment of polylimide films, J. Vac. Sci. Technol. A 7 (1989) 2709-2716. 
417 [14] D.R. Baer, J.F. Moulder, High resolution XPS spectrum of calcite $\left(\mathrm{CaCO}_{3}\right)$, Surf. Sci. Spect. 2 (1993) 1-2.

[15] H. Estrade-Szwarckopf, XPS photoemission in carbonaceous materials: a "defect" peak beside the graphitic asymmetric peak, Carbon 42 (2004) 1713-1721.

[16] U. Gelius, P. F. Hedén, J. Hedman, B. J. Lindberg, R. Manne, R. Nordberg, C. Nordling, K. Siegbahn, Molecular Spectroscopy by Means of ESCA, Phys. Scr. 2 (1970) 70-80.

[17] J. Bartoll, R. Stößer, M. Nofz, Generation and conversion of electronic defects in calcium

carbonates by UV/Vis light, Appl. Radiat. Isot.52 (2000) 1099-1105.

[18] A. Putnis, B. Winkler, L. Fernandez-Diaz, In situ IR spectroscopic and thermogravimetric study of the dehydration of gypsum, Mineralogical Magazine 54 (1990) 123-128.

[19] P.J. Larkin, Infrared and raman spectroscopy: principles and spectral interpretation, Elsevier, Oxford, 2011, pp. 73-117.

[20] C. Russo, F. Stanzione, A. Tregrossi, A. Ciajolo, Infrared spectroscopy of some carbon-based materials relevant in combustion: Qualitative and quantitative analysis of hydrogen, Carbon 74 (2014) 127-138.

[22] P. Parent, C. Laffon, I. Marhaba, D. Ferry, T.Z. Regier, I.K. Ortega, B. Chazallon, Y. Carpentier, C. Focsa, Nanoscale characterization of aircraft soot: A high-resolution transmission electron microscopy, Raman spectroscopy, X-ray photoelectron and near-edge X-ray absorption spectroscopy study, Carbon 101 (2016) 86-100.

[23] J.P. Abrahamson, M. Singh, J.P. Mathews, R.L. Vander Wal, Pulsed laser annealing of carbon black, Carbon 124 (2017) 380-390.

[24] H.P. Michelsen, A.V. Tivanski, M. K. Gilles, L.H. van Poppel, M.A. Dansson, P.R. Buseck, Particle formation from pulsed laser irradiation of soot aggregates studied with a scanning mobility particle 

sizer, a transmission electron microscope, and a scanning transmission x-ray microscope, Applied Optics 46 (2007) 959-977.

[25] A.C. Tam, W.P. Leung, W. Zapka, W. Ziemlich, Laser cleaning techniques for removal of surface particulates, J. appl. Phys. 71 (1992) 3515-3523.

[26] A. Oberlin, Carbonization and graphitization, Carbon 22 (1984) 521-541.

[27] Z. Yan, Z. Wang, X. Wang, H. Liu, J. R. Qiu, Kinetic model for calcium sulfate decomposition at high temperature, Trans. Nonferrous Met. Soc. China 25 (2015) 3490-3497.

[28] J.-F. Rontani, P. J. -P. Giral, Significance of photochemical degradation of petroleum hydrocarbon fractions in seawater, Intern. J. Environ. Anal. Chem. 42 (1990) 61-68.

[29] J.M. Miller, D. Olejnik, Photolysis of polycyclic aromatic hydrocarbons in water, Wat. Res. 35 (2001) 233-243.

[30] M. Li, F. Bao, Y. Zhang, W. Song, C. Chen, J. Zhao, Role of elemental carbon in the photochemical aging of soot, Proc. Nat. Acad. Sci. 115 (2018) 7717-7722.

[31] H. Michelsen, Understanding and predicting the temporal response of laser-induced incandescence from carbonaceous particles, J. Chem. Phys. 118 (2003) 7012-7045.

[32] E.V. Barmina, A.V. Simakin, G.A. Shafeev, Hydrogen emission under laser exposure of colloidal solutions of nanoparticles, Chem. Phys. Lett. 655-656 (2016) 35-38.

[33] I. Akimoto, K. Maeda, N. Ozaki, Hydrogen generation by laser irradiation of carbon powder in water, J. Phys. Chem. C 117 (2013) 18281-18285.

[34] A.E. Krauklis, A.T. Echtermeyer, Mechanism of Yellowing: Carbonyl Formation during Hygrothermal Aging in a Common Amine Epoxy, Polymers 10 (2018), 1017.

[35] P. Pouli, M. Oujja, M. Castillejo, Practical issues in laser cleaning of stone and painted artifacts: optimization procedures and side effects, Appl. Phys. A 106 (2012) 447-464. 


\section{SUPPLEMENTARY MATERIAL}

\section{Yellowing of laser-cleaned artworks: formation of residual hydrocarbon compounds after Nd:YAG laser cleaning of gypsum plates covered by lamp black.}

Jeremie BERTHONNEAU ${ }^{1 *}$, Philippe PARENT ${ }^{1 *}$, Olivier GRAUBY ${ }^{1}$, Daniel FERRY ${ }^{1}$, Carine LAFFON ${ }^{1}$, Alain COLOMBINI ${ }^{2}$, Blandine COURTOIS ${ }^{1}$ and Philippe BROMBLET ${ }^{2}$

${ }^{1}$ Aix-Marseille Université, CNRS - UMR 7325 CINaM (Centre Interdisciplinaire de Nanoscience de Marseille), Campus de Luminy, 13288 Marseille Cedex 9, France.

${ }^{2}$ CICRP Belle de Mai, 21 rue Guibal, 13003 Marseille, France.

*Corresponding authors, e-mail: parent@cinam.univ-mrs.fr; berthonneau@cinam.univ-mrs.fr 


\section{$\underline{\text { S1. C1s and O1s XPS }}$}

Fig. S1 presents the C1s (left panel) and O1s (right panel) data of the bare gypsum plate (bottom), the lamp black particles (top), and those of Areas 1-3 (covered with lamp black; after laser cleaning; after laser cleaning + UV), whose C1s data are shown also Fig. 2 of the article.
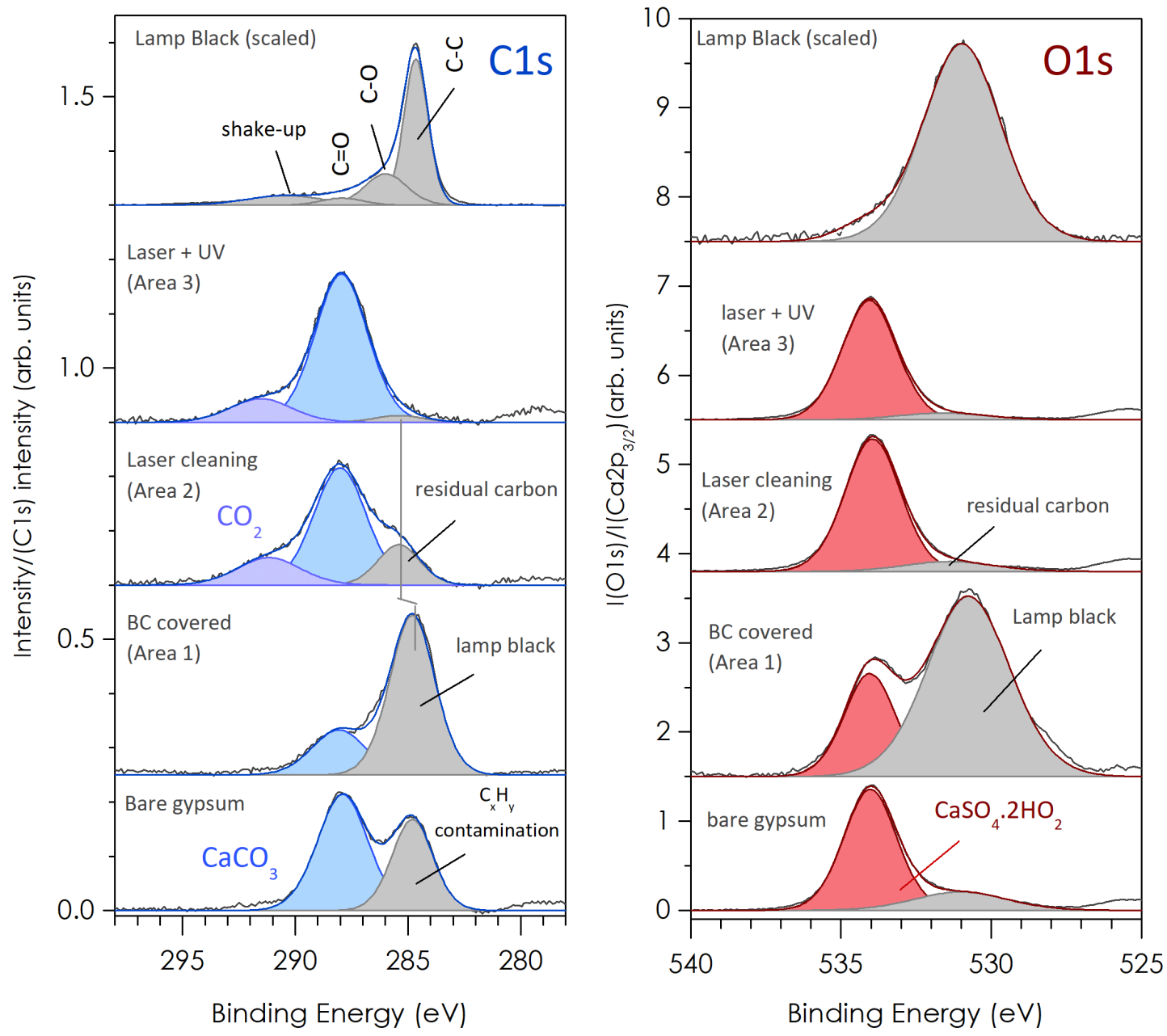

Figure S1. Deconvoluted C1s (left) and O1s (right) XPS lines of bare gypsum (bottom), of Areas 1-3 and lamp black (top).

\section{a/ C1s XPS spectra}

The $\mathrm{C} 1 \mathrm{~s}$ spectra are normalized to their integrated intensity to allow for their comparison. 
-The C1s spectrum of the lamp black particles is scaled for display (left panel, top). It is deconvoluted in 4 components [1] : the most intense peak at $284.8 \mathrm{eV}$ is related to $\mathrm{C}-\mathrm{C}$ bonds of the graphitic layers of the primary particles. The shake-up (or plasmon) peak at $290.3 \mathrm{eV}$ results from this graphitic nature. The lamp black particles are also oxidized, as shown by the two contributions of oxidized carbon at $286.0 \mathrm{eV}(\mathrm{C}-\mathrm{O})$ and $287.9 \mathrm{eV}(\mathrm{C}=\mathrm{O})$.

- The C1s spectrum of the bare gypsum plate (left panel, bottom) presents a peak at 284.8 $\mathrm{eV}$, typical of adventitious hydrocarbons $\mathrm{C}_{\mathrm{x}} \mathrm{H}_{\mathrm{y}}$, and a second one at $288.0 \mathrm{eV}$ assigned to $\mathrm{CaCO}_{3}$ $[2,3]$ contaminating the gypsum plate. This peak could hide some oxidized groups belonging to the adventitious carbon species, if any.

- The $\mathrm{C} 1 \mathrm{~s}$ spectrum of Area 1 is made of two peaks. The one at $288.0 \mathrm{eV}$ is assigned to $\mathrm{CaCO}_{3}$ visible through holes in the lamp black crust, and the second at $284.8 \mathrm{eV}$ assigned to the lamp black peak. This peak certainly contains a (attenuated) contribution of the adventitious carbon detected on the bare gypsum plate $(284.8 \mathrm{eV})$, which will also be visible through these holes. The $\mathrm{C} 1 \mathrm{~s}$ peak at $284.8 \mathrm{eV}$ is fitted with a broad single component, and therefore the slight oxidized part of the lamp black spectrum is not simulated.

- The C1s spectra of Area 2 and 3 are made of three peaks. The most intense peak at $288.0 \mathrm{eV}$ is the $\mathrm{CaCO}_{3}$ peaks, which increases relatively to the lamp black contribution after laser cleaning (Area 2) as the particles are ablated, and after UV exposure (Area 3). As explained in the article, the second peak at $285.5 \mathrm{eV}$ is assigned to the neo-formed phase of carbon that redeposits after laser ablation/vaporization (residual carbon, Area 2). The UV exposure makes it almost completely disappear (Area 3). The $\mathrm{CO}_{2}$ peak at $291.6 \mathrm{eV}$ is a side effect, due to the laser decomposition of $\mathrm{CaCO}_{3}$ (see main text).

\section{b/ O1s XPS spectra}

The O1s spectra are normalized to the integrated intensity of the $\mathrm{Ca} 2 \mathrm{p}_{3 / 2}$ peak (except for lamp black) to allow for their comparison. The raw O1s spectrum of lamp black is scaled for display.

-The O1s spectrum of the lamp black particles (right panel, top) is a single peak at 530.8 $\mathrm{eV}$, which includes the two contributions of the oxidized carbon groups $(\mathrm{C}=\mathrm{O}$ and $\mathrm{C}-\mathrm{O})$ [4].

- The O1s spectrum of the bare gypsum plate (right panel, bottom) presents a main peak at $533.9 \mathrm{eV}$ assigned to gypsum $\mathrm{CaSO}_{4} \cdot 2 \mathrm{H}_{2} \mathrm{O}$, that might include a weak contribution of $\mathrm{CaCO}_{3}$ 
(energy calibration differs from [5]), and a broad one at $530.8 \mathrm{eV}$ related to the oxidized carbon groups of the adventitious carbon species contaminating the gypsum plate.

- The O1s spectrum of Area 1 presents a substrate peak $\left(\mathrm{CaSO}_{4} \cdot 2 \mathrm{H}_{2} \mathrm{O}\right)$ - pointing out from the holes of the lamp black particles-, and a contribution of the oxidized carbon groups of lamp black at $530.8 \mathrm{eV}$.

- The O1s spectra of Area 2 and 3 are made of two peaks. The most intense peak at 533.9 $\mathrm{eV}$ is that of gypsum $\mathrm{CaSO}_{4} \cdot 2 \mathrm{H}_{2} \mathrm{O}$. The peak at $530.8 \mathrm{eV}$ strongly decreases after laser ablation/vaporization (Area 2). We assign it as mainly due to the oxidized part of the neoformed phase (labelled "residual carbon"), eventually bleached after the UV treatment (Area $3)$.

The O1s evolution of the carbon oxide peaks from Area 1 to Area 3 is fully consistent with that of the $\mathrm{C} 1 \mathrm{~s}$ peak at $284.8 \mathrm{eV}$ related to the lamp black particles contribution before/after ablation/vaporization and the subsequent UV exposure.

\section{References}

[1] H. Estrade-Szwarckopf, XPS photoemission in carbonaceous materials: A “defect” peak beside the graphitic asymmetric peak, Carbon. 42 (2004) 1713-1721. doi:10.1016/j.carbon.2004.03.005.

[2] D.R. Baer, J.F. Moulder, High Resolution XPS Spectrum of Calcite $\left(\mathrm{CaCO}_{3}\right)$, Surf. Sci. Spectra. 1 (2015). doi:10.1116/1.1247719.

[3] B. Demri, D. Muster, XPS study of some calcium compounds, J. Mater. Process. Technol. 55 (1996) 311-314.

[4] J.O. Müller, D.S. Su, U. Wild, R. Schlögl, Bulk and surface structural investigations of diesel engine soot and carbon black, Phys. Chem. Chem. Phys. 9 (2007) 4018-4025. doi:10.1039/b704850e.

[5] C.D. Wagner, D. Zatko, R. Raymon, Use of the Oxygen KLL Auger Lines in Identification of Surface Chemical States by Electron Spectroscopy for Chemical Analysis, Anal. Chem. 52 (1980) 1445-1451. doi:10.1021/ac50059a017. 